\title{
Ablasi Radiofrekuensi pada Neuralgia Trigeminal dengan Panduan Fluoroskopi
}

\section{Radiofrequency Ablation in Trigeminal Neuralgia with Fluoroscopic Guidance}

Wignyo Santosa ${ }^{\varpi}$

Bagian Ilmu Anestesi, Fakultas Kedokteran, Universitas Islam Sultan Agung, Semarang, Indonesia

${ }^{\square}$ Korespondensi:wgnsantosa@gmail.com

\begin{abstract}
Background: Trigeminal neuralgia is the most severe pain in the world, revealed by Peter J. Jannetta, MD. The pathophysiology of trigeminal neuralgia is still unclear.

Case: A 59-year-old man came to the pain clinic with complaints of severe pain on the right face diagnosed with trigeminal neuralgia. The patient visited the clinic with severe pain and vases $>8$. To reduce pain immediately, a local anaesthetic block with ultrasound guidance (USG) was performed. Radiofrequency $(R F)$ ablation of the trigeminal nerve with fluoroscopic guidance $(C$-arm) was administered to patient. This case report aims to report the benefits of $R F$ therapy with fluoroscopic guidance in reducing severe pain.

Discussion: Stimulation parameters were measured to conclude the effectiveness of the therapy, such as motor function: there should be little or no contraction of the masseter musculus, patients could be awakened and feel the stimulation by stopping propofol sedation and sensory stimulation could be done at $50 \mathrm{~Hz}$. Paraesthesia should be felt between 0.05 and $0.2 \mathrm{~V}$ in the area corresponding to the patient's pain. After proper paraesthesia, the temperature is set at $60^{\circ} \mathrm{C}, R F$ therapy can be carried out for 60 seconds and could be repeated again at the same temperature $\left(60^{\circ} \mathrm{C}\right)$. Corneal reflexes were tested and patients were evaluated for hypoesthesia according to their dermatomes. The third $R F$ was performed at $65^{\circ} \mathrm{C}$ for 60 seconds, and the fourth $R F$ was done at $70^{\circ} \mathrm{C}$ for 60 seconds. For this patient, fluoroscopic guidance of RF therapy was carried out on trigeminal neuralgia (V1, V2, V3) with satisfying result, when the patient visited the clinic his visual analog scale $(V A S)>8$, after getting RF therapy his VAS value dropped to 0. Conclusion: $R F$ treatment recommendations for cases of trigeminal neuralgia was $2 B+$. Patients with severe chronic pain due to trigeminal neuralgia and getting $R F$ therapy with fluoroscopic guidance got very satisfying results, marked by a very significant decrease in VAS from VAS >8 to 0.
\end{abstract}

Keywords: anaesthesia; fluoroscopic guidance; radiofrequency ablation; trigeminal neuralgia; VAS score 


\begin{abstract}
ABSTRAK
Latar belakang: Neuralgia trigeminal adalah nyeri yang paling berat yang ada di dunia, diungkapkan oleh Peter J. Jannetta, MD. Patofisiologi neuralgia trigeminal masih tidak jelas.

Kasus: Seorang pria 59 tahun datang ke klinik nyeri dengan keluhan nyeri hebat pada wajah sebelah kanan didiagnosa dengan neuralgia trigeminal. Pasien datang ke klinik dengan nyeri hebat dan visual analog scale (VAS) $>8$. Untuk mengurangi nyeri dengan segera, dilakukan blok anestesi lokal dengan panduan ultrasonografi (USG). Ablasi radiofrekuensi (RF) pada nervus trigeminal dengan panduan fluoroskopi $(C$-arm) diberikan kepada pasien. Laporan kasus ini bertujuan untuk melaporkan manfaat terapi RF dengan panduan fluoroskopi dalam meredakan nyeri berat.

Pembahasan: Parameter stimulasi diukur untuk menyimpulkan efektivitas terapi, seperti fungsi motorik: harus ada sedikit atau tidak ada kontraksi dari otot masseter, pasien dapat dibangunkan dan merasakan rangsangan stimulasi, dengan menghentikan sedasi propofol, dan stimulasi sensorik dapat dilakukan pada $50 \mathrm{~Hz}$. Parestesia harus dirasakan antara 0,05 dan $0,2 \mathrm{~V}$ di daerah yang sesuai dengan lokasi nyeri pasien. Setelah parestesia yang tepat, suhu dipasang pada $60^{\circ} \mathrm{C}$, terapi RF bisa dilakukan selama 60 detik dan dapat diulang lagi pada suhu yang sama $\left(60^{\circ} \mathrm{C}\right)$. Refleks kornea diuji dan pasien dievaluasi terjadinya hypoesthesia sesuai dermatomnya. Dilakukan $\mathrm{RF}$ ketiga pada $65^{\circ} \mathrm{C}$ selama 60 detik, dan RF keempat dilakukan pada $70^{\circ} \mathrm{C}$ selama 60 detik. Pada pasien ini dilakukan terapi RF dengan panduan fluoroskopi pada (V1, V2, V3) dengan hasil yang sangat memuaskan, ketika pasien datang ke klinik nilai visual analog scale (VAS) nya >8, setelah mendapatkan terapi RF nilai VAS nya turun menjadi 0 .

Kesimpulan: Rekomendasi pengobatan RF untuk kasus neuralgia trigeminal adalah $2 \mathrm{~B}+$. Pasien dengan nyeri kronis berat akibat neuralgia trigeminal dan mendapatkan terapi RF dengan panduan fluoroskopi mendapatkan hasil yang sangat memuaskan, ditandai dengan penurunan VAS yang sangat berarti dari VAS saat datang $>8$ menjadi 0 .
\end{abstract}

Kata Kunci: ablasi radiofrekuensi ; anestesi; neuralgia trigeminal; panduan fluoroskopi; skor VAS

\section{PENDAHULUAN}

Neuralgia trigeminal adalah nyeri yang paling berat yang ada di dunia, diungkapkan oleh Peter J. Jannetta, MD dengan istilah striking back, sebuah pengalaman orang awam untuk pasien dengan nyeri wajah. ${ }^{1}$ Neuralgia trigeminal, atau tic doloureux, adalah kondisi yang menyakitkan dari wajah. Nyeri ini telah dikenal sejak zaman kuno, terdapat deskripsi nyeri wajah oleh Ibnu Sina (980-1073) dalam literatur Arab. ${ }^{2}$ Sebuah contoh dari intervensi pengobatan awal oleh Locke pada tahun
1677, yang mengoleskan asam sulfat kepada wajah Duchess of Northumberland dalam upayanya untuk mengobati neuralgia trigeminal yang ia derita. $^{1}$

Sebuah survei yang dilakukan di 6 negara Eropa menunjukkan bahwa neuralgia trigeminal secara signifikan berdampak pada kualitas hidup dan fungsi sosial ekonomi pasien yang terkena. ${ }^{3}$ Neuralgia trigeminal adalah bentuk paling umum dari nyeri wajah pada orang tua berusia 50 tahun. $^{4}$ Berbagai penelitian epidemiologi 
menunjukkan kejadian tahunan sekitar 4-5 pasien baru per 100.000. Insiden tertinggi terjadi pada usia antara 50 dan 70 tahun, dalam $90 \%$ kasus gejala dimulai setelah usia 40 tahun. Neuralgia trigeminal lebih umum pada wanita dibandingkan pria dengan rasio 1,5: $1 .^{1}$

Patofisiologi neuralgia trigeminal masih tidak jelas. Berdasarkan pengamatan klinis, nervus trigeminus yang berasal dari batang otak, yang disebut root entry zone, oleh pembuluh darah atau tumor mengalami kompresi sehingga dapat menyebabkan neuralgia trigeminal. Tekanan lokal menyebabkan demyelinisasi yang mengarah ke depolarisasi abnormal menimbulkan impuls ektopik. ${ }^{1}$ Distribusi rasa sakit di berbagai cabang nervus trigeminus diberikan dalam Tabel 1. Penekanan saraf trigeminal bisa oleh neuroma akustik, kolesteatum, aneurisma, angioma, dan kelainan tulang. Derajat nyerinya hampir sama dengan nyeri kepala cluster (sedang hingga sangat berat). ${ }^{5}$ Nyeri yang tidak terkontrol bisa memnimbulkan keadaan darurat. Serangan bisa dipicu oleh kegiatan sehari-hari yang melibatkan kontak dengan daerah wajah seperti menyikat gigi, mencukur, atau mencuci muka. Nyeri bisa terkendali dengan terapi medikamentosa pada sebagian besar pasien. 2-3\% dari pasien-pasien dengan neuralgia trigeminal juga mengalami multiple sclerosis. ${ }^{6}$ International Headache Society telah menyarankan kriteria diagnostik mereka sendiri untuk neuralgia trigeminal (Tabel 2).

Tabel 1. Distribusi variasi nyeri cabang nervus di neuralgia trigeminal

\begin{tabular}{cc}
\hline Hanya V1 & $4 \%$ \\
\hline Hanya V2 & $17 \%$ \\
\hline Hanya V3 & $15 \%$ \\
\hline V2 + V3 & $32 \%$ \\
\hline
\end{tabular}

\begin{tabular}{cc}
\hline $\mathrm{V} 1+\mathrm{V} 2$ & $14 \%$ \\
\hline $\mathrm{V} 1+\mathrm{V} 2+\mathrm{V} 3$ & $17 \%$ \\
\hline
\end{tabular}

Tabel 2. Neuralgia trigeminal: kriteria diagnosis klinis

\begin{tabular}{|c|c|}
\hline Karakteristik & Deskripsi \\
\hline Karakter & $\begin{array}{l}\text { Menusuk, seperti hantaran } \\
\text { listrik, dan superfisial }\end{array}$ \\
\hline Keparahan & $\begin{array}{l}\text { Intensitas sedang hingga } \\
\text { berat }\end{array}$ \\
\hline Durasi & $\begin{array}{l}\text { Setiap serangan nyeri dapat } \\
\text { hanya terjadi dalam beberapa } \\
\text { detik tetapi setiap serangan } \\
\text { dapat terjadi secara simultan } \\
\text { setelah terdapat interval bebas } \\
\text { nyeri }\end{array}$ \\
\hline Periode & $\begin{array}{l}\text { Periode tanpa nyeri dapat } \\
\text { terjadi beberapa minggu } \\
\text { hingga beberapa bulan }\end{array}$ \\
\hline Lokasi & $\begin{array}{l}\text { Distribusi dari neuralgia } \\
\text { trigeminal, terutama } \\
\text { unilateral }\end{array}$ \\
\hline $\begin{array}{l}\text { Awal } \\
\text { kemunculan }\end{array}$ & $\begin{array}{l}\text { Daerah nervus } \\
\text { trigeminus }\end{array}$ \\
\hline Faktor pencetus & $\begin{array}{l}\text { Sentuhan ringan, seperti } \\
\text { makan, berbicara atau } \\
\text { membasuh }\end{array}$ \\
\hline $\begin{array}{l}\text { Faktor } \\
\text { memperingan }\end{array}$ & Tidur, anti-epilepsi \\
\hline $\begin{array}{l}\text { Karakteristik yang } \\
\text { berdampingan }\end{array}$ & $\begin{array}{l}\text { Daerah pencetus, penurunan } \\
\text { berat badan, kualitas hidup } \\
\text { yang buruk, depresi }\end{array}$ \\
\hline
\end{tabular}

Terapi pasien dengan neuralgia trigeminal esensial sebaiknya multidisiplin dan beragam pilihan terapi harus didiskusikan menyangkut risiko kepada pasien. Pasien tua dengan penyakit-penyakit komorbid, maka terapi radiofrekuensi (RF) pada ganglion gasseri dapat direkomendasikan. Pada pasien dengan usia lebih muda, menurut Janetta, microvascular decompression (MVD) sebaiknya jadi pertimbangan pilihan. ${ }^{1,7}$

\section{KASUS}

Seorang laki-laki umur 59 tahun datang ke klinik nyeri dengan keluhan nyeri 
hebat pada wajah sebelah kanan. Serangan nyeri berulang, setiap serangan berlangsung selama 5 menit dan bisa berulang tiap 10 menit kemudian. Nyeri dipicu pada waktu menggosok gigi dan makan. Penderita mengalami nyeri wajah seperti ini sudah lebih dari 1 tahun. Penderita sulit tidur, karena nyeri yang tidak tertahankan kadang disertai keluarnya air mata. Sudah pernah berobat ke beberapa dokter dan hanya diberikan obat anti nyeri tapi tidak ada perubahan yang berarti, bahkan pernah berobat ke dokter gigi yang akibatnya seluruh gigi atas dan bawah sebelah kanan di cabut semua. Penderita juga mengalami gangguan makan karena nyerinya.

Pada pemeriksaan, penderita merasakan nyeri pada daerah lidah dan rongga mulut bahkan sampai ke pipi. Nyeri dirasakan seperti di tusuk-tusuk atau terasa perih dan kadang-kadang dirasakan seperti terbakar. Tidak ada muntah proyektil dan gangguan keseimbangan. Tidak didapatkan nyeri tekan di daerah tempuromandibula joint. Tidak ada keringat yang berlebihan. Kemudian penderita didiagnosa dengan neuralgia trigeminal (V1, V2, V3).

Karena pasien datang dengan nyeri hebat dan vas $>8$, sehingga untuk mengurangi nyeri dan menolong pasien dengan segera, dilakukan blok anestesi lokal dengan panduan ultrasonografi (USG) pada daerah supraorbita, infraorbita, mentalis, dan auriculartemporal. Masing-masing diberikan lidokain 2\% $20 \mathrm{mg}$. Setelah dilakukan blok tersebut dan dievaluasi, penderita merasakan nyeri mulai berkurang. Kemudian direncanakan untuk dilakukan ablasi radiofrekuensi (RF) pada nervus trigeminal dengan panduan fluoroskopi (C-arm).
Prosedur ini menggunakan fluoroskopi untuk alat bantu pencitraan sekaligus sebagai pemandu terapi. ${ }^{8}$ Pasien diposisikan supine dengan kepala ekstensi untuk mengurangi sudut fluoroskopi dari arah submental. Pertama, C-arm diarahkan ke arah submental (Gambar 1), lalu dirotasikan oblik ke sisi ipsilateral (Gambar 3) hingga ditemukan foramen ovale (Gambar 2) dengan bentuk oval di bagian medial dari angulus mandibular dan lateral dari maksila.

Entry point dari jarum RF tergantung dari cabang nervus trigeminal yang dituju. Entry point menuju cabang mandibularis dan maksilaris adalah 2 centimeter ke lateral dari sudut mulut ipsilateral dengan target akhir posisi jarum (Gambar 4) di tengah dari foramen ovale. Jika sasaran dituju hanya cabang mandibularis, maka entry point adalah 1 $\mathrm{cm}$ ke lateral sudut mulut ipsilateral dengan ujung jarum berada di sisi lateral dari foramen ovale. Sedangkan entry point untuk cabang oftalmikus adalah 3 $\mathrm{cm}$ ke lateral sudut mulut ipsilateral dengan target ujung jarum berada di tepi medial dari foramen ovale. Propofol digunakan dengan dosis $1 \mathrm{mg} / \mathrm{kg}$ BB ketika insersi jarum RF ukuran $10 \mathrm{~cm}$, $22 \mathrm{G}$ dengan ujung aktif $2 \mathrm{~mm} .1$ jari berada di rungga mulut area bukal untuk kendali supaya jarum RF tidak menembus rongga mulut yang mengkontaminasi jarum. 


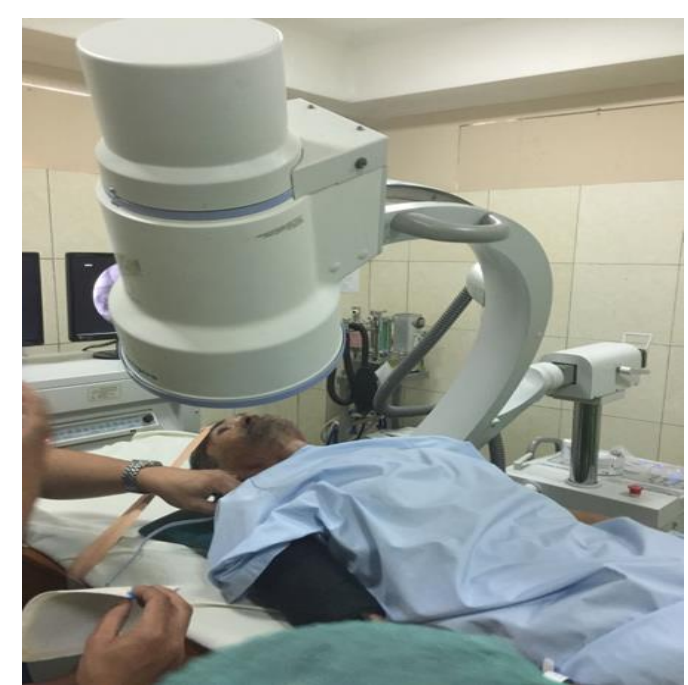

Gambar 1. Pandangan submental

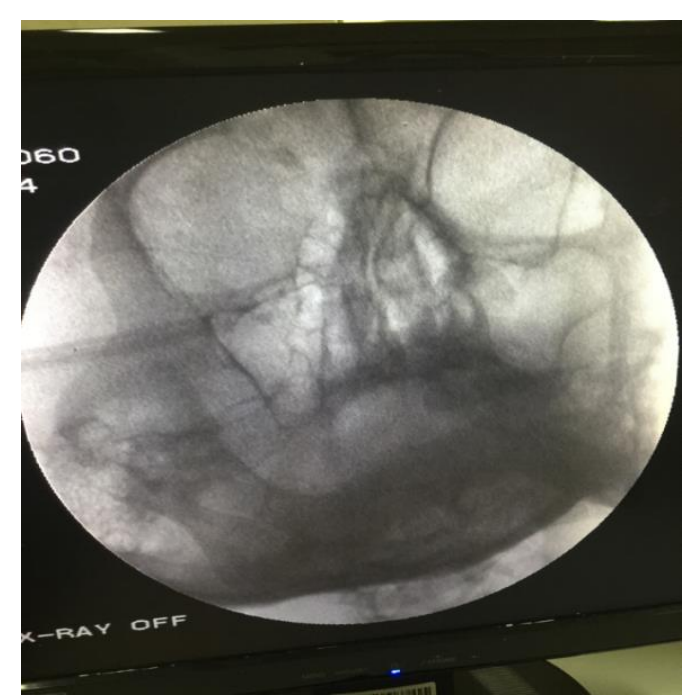

Gambar 2. Foramen ovale

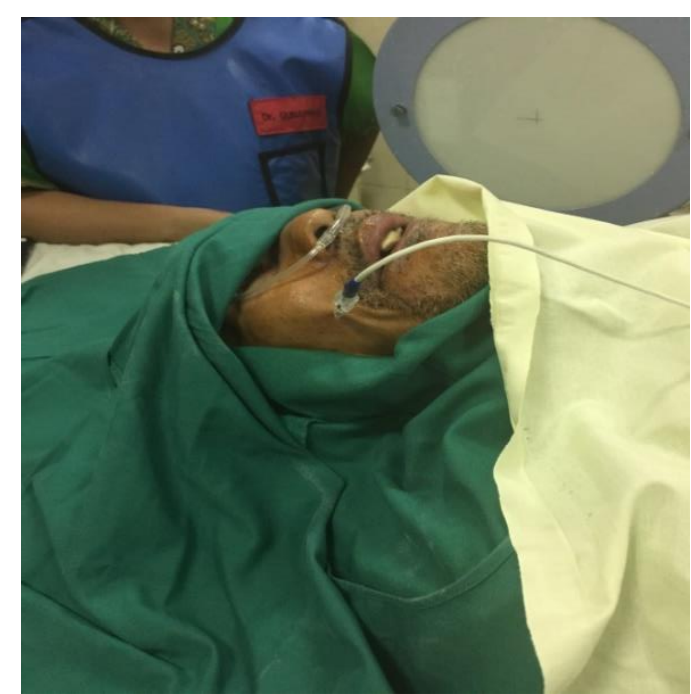

Gambar 3. Pandangan lateral

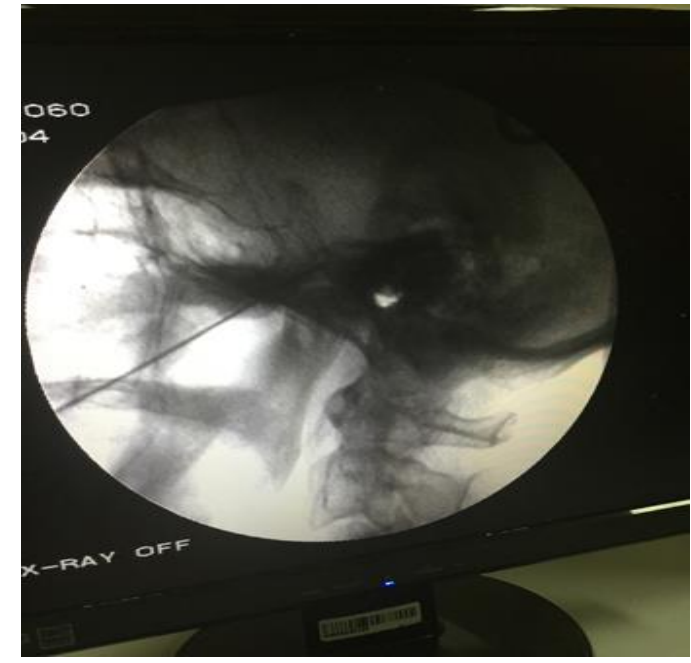

Gambar 4. Target ujung jarum

Menggunakan 2 lapis sarung tangan sehingga setelah jarum dipastikan tidak menembus rongga mulut, sarung tangan yang kontak dengan rongga mulut langsung dilepas dan lapisan berikutnya adalah steril. Hasil ideal jika jarum berada pada posisi tunnel view pada fluoroskopi. Hal ini penting untuk menempatkan jari di mulut untuk memastikan bahwa tidak ada penetrasi dari mukosa mulut. Begitu jarum melalui foramen ovale ke rongga meckel, stimulasi dapat terjadi. ${ }^{1}$

Parameter stimulasi adalah sebagai berikut: pertama fungsi motorik diuji, dimana harus ada sedikit atau tidak ada kontraksi otot masseter, sebaiknya di atas ambang batas 0,6 V. Dengan stimulasi motorik, jarum harus maju dengan hati-hati sekitar $2 \mathrm{~mm}$. Pasien dapat dibangunkan dan merasakan rangsangan stimulasi, dengan menghentikan sedasi propofol, dan stimulasi sensorik dapat dilakukan pada $50 \mathrm{~Hz}$. Parestesia harus merasa antara 0,05 dan $0,2 \mathrm{~V}$ di daerah yang sesuai dengan nyeri pasien. Setelah parestesia yang tepat, suhu dipasang pada $60^{\circ} \mathrm{C}$, terapi RF bisa dilakukan selama 60 detik. Kemudian diulang lagi pada suhu yang sama $\left(60^{\circ} \mathrm{C}\right)$. Setelah itu, refleks kornea 
diuji dan pasien dievaluasi terjadinya hypoesthesia sesuai dermatomnya. Dilakukan RF ketiga pada $65^{\circ} \mathrm{C}$ selama 60 detik, dan RF keempat dilakukan pada $70^{\circ} \mathrm{sC}$ selama 60 detik.

\section{PEMBAHASAN}

Pasien datang ke klinik nyeri dengan diagnosa nyeri kronik berat yang disebabkan oleh neuralgia trigeminal. Pasien ini sudah memenuhi kriteria diagnosa neuralgia trigeminal antara lain nyeri timbul dalam bentuk serangan, sebagian serangan terjadi dalam durasi sangat singkat (beberapa detik hingga beberapa menit), terjadi nyerinya unilateral, daerah nyerinya didaerah nervus trigeminal (V1, V2, V3) dan tidak ada gejala otonom unilateral. Pada pasien ini idealnya harus dilakukan pemeriksaan penunjang radiografi (MRI/ CT-scan) untuk menyingkirkan penyebab neuralgia trigeminal seperti multiple sclerosis dan tumor cerebelopontin angle. Pada pemeriksaan klinis pasien ini tidak didapatkan adanya keluhan pasien yang mengarah ke kelainan tersebut, dan juga tidak didapatkan adanya defisit nervus fisiologis $\mathrm{n} V$ dan $\mathrm{n}$ cranialis yang lain. Sedangkan pertimbangan pemilihan terapi ablasi ganglion gasserian dengan RF adalah karena pada pasien ini sudah mendapatkan terapi medikamentosa yang lama dan tidak mendapatkan hasil yang baik, dan juga dipilih karena pertimbangan pasien yang sudah berumur 59 tahun, daripada dilakukan tindakan operasi (MVD), yang akan mengakibatkan lebih banyak terjadi komplikasi akibat anestesi dan pembedahan. ${ }^{5}$ Apabila pasien muda mungkin pemilihan MVD lebih baik. Pasien datang dengan nyeri hebat sehingga segera dilakukan blok anestesi lokal dengan panduan ultrasonografi (USG) pada daerah yang merupakan jarak dari nervus trigeminal pada fosa supraorbita, infraorbita, mentalis dan sekitar auriculartemporal untuk mengurangi nyeri, hal ini sesuai dengan anatomi dari nervus trigeminal dimana persarafan di frontal dibentuk oleh saraf supraorbita dari dahi dan kulit kepala dan nervus supratrochlear dari hidung, bagian tengah dari palpebra dan bagian tengah dahi. Serabut sensoris kecil dari sinus frontalis bersamaan dengan nervus frontal di bagian anterior orbita. Saraf sensorik dari dagu dan bibir bagian bawah bertemu untuk membentuk nervus mentalis, yang memasuki mandibula disepanjang foramen mentalis untuk melewati kanal mandibularis. ${ }^{49}$ Di dalam kanal, cabang dari dental gigi bawah dengan nervus mentalis dan membentuk nervus alveolaris inferior. Nervus ini berlanjut ke bagian posterior and keluar ke bagian mandibularis disepanjang nervus lingual. Nervus auriculotemporal, yang berjalan dengan arteri temporal superfisialis, membawa sensasi dari sisi kepala dan kulit kepala. Ketiga bagian dari nervus trigeminal, nervus oftalmikus, mandibular dan maksilaris bergabung bersama menuju ganglion trigeminal dimana terdapat sebagian besar badan sel saraf sensorik berada. Central process dari neuron-neuron ini merupakan serabut sensorik dan nervus trigeminus, yang memasuki pons pada midlateral point. Axon-axon terminalis oleh sinaps dengan urutan kedua neuron sensorik tepatnya di regio nukleus trigeminal. ${ }^{10,11}$

Pada pasien ini dilakukan terapi RF dengan panduan fluoroskopi. Pada pasien ini dilakukan terapi RF pada neuralgia trigeminal (V1, V2, V3) dengan hasil yang sangat memuaskan, penderita pada saat datang nilai VAS nya $>8$ sedangkan setelah mendapatkan terapi RF nilai VAS nya turun menjadi 0 . 
Rekomendasi pengobatan radiofrekuensi untuk kasus neuralgia trigeminal adalah 2B+ (Tabel 3). ${ }^{4}$

Tabel 3. Kesimpulan bukti manajemen neuralgia trigeminal di seluruh dunia

\begin{tabular}{lc}
\hline \multicolumn{1}{c}{ Teknik } & Penilaian \\
$\begin{array}{l}\text { Pengobatan } \\
\text { radiofrekuensi } \\
\text { ganglion gasserian }\end{array}$ & $2 \mathrm{~B}+$ \\
$\begin{array}{l}\text { Pengobatan } \text { pulsed } \\
\text { radiofrequency } \text { ganglion } \\
\text { gasserian }\end{array}$ & $2 \mathrm{~B}-$ \\
Lihat Zundert et al. $^{1}$ &
\end{tabular}

\section{KESIMPULAN}

Kasus neuralgia trigeminal klasik (esensial) dapat didiagnosis dengan mengajukan 6 pertanyaan sederhana (Tabel 4). Penting diperhatikan bahwa MRI perlu dilakukan pada setiap pasien, untuk menyingkirkan neuralgia trigeminal sekunder yang memerlukan perawatan kausal lebih banyak, sebelum beralih ke terapi invasif. Pilihan pengobatan pertama (medikamentosa) adalah karbamazepin. Pada pasien yang lebih muda dengan neuralgia trigeminal, pilihan pertama pengobatan invasif mungkin MVD. Sedangkan pada pasien lansia, pengobatan RF ganglion gasserian merupakan rekomendasi. ${ }^{1}$

Pada penderita dengan nyeri wajah yang sudah refrakter dengan pengobatan medikamentosa perlu dipikirkan adanya neuralgia trigeminal. Pada pasien ini yang diagnosa sebagai nyeri kronis berat akibat neuralgia trigeminal dan mendapatkan terapi RF pada neuralgia trigeminal dengan panduan fluoroskopi mendapatkan hasil yang sangat memuaskan, hal ini ditandai dengan penurunan VAS yang sangat berarti dari VAS saat datang $>8$ dan setelah mendapatkan terapi VAS turun menjadi 0 .

Tabel 4. Diagnosis banding neuralgia trigeminal.

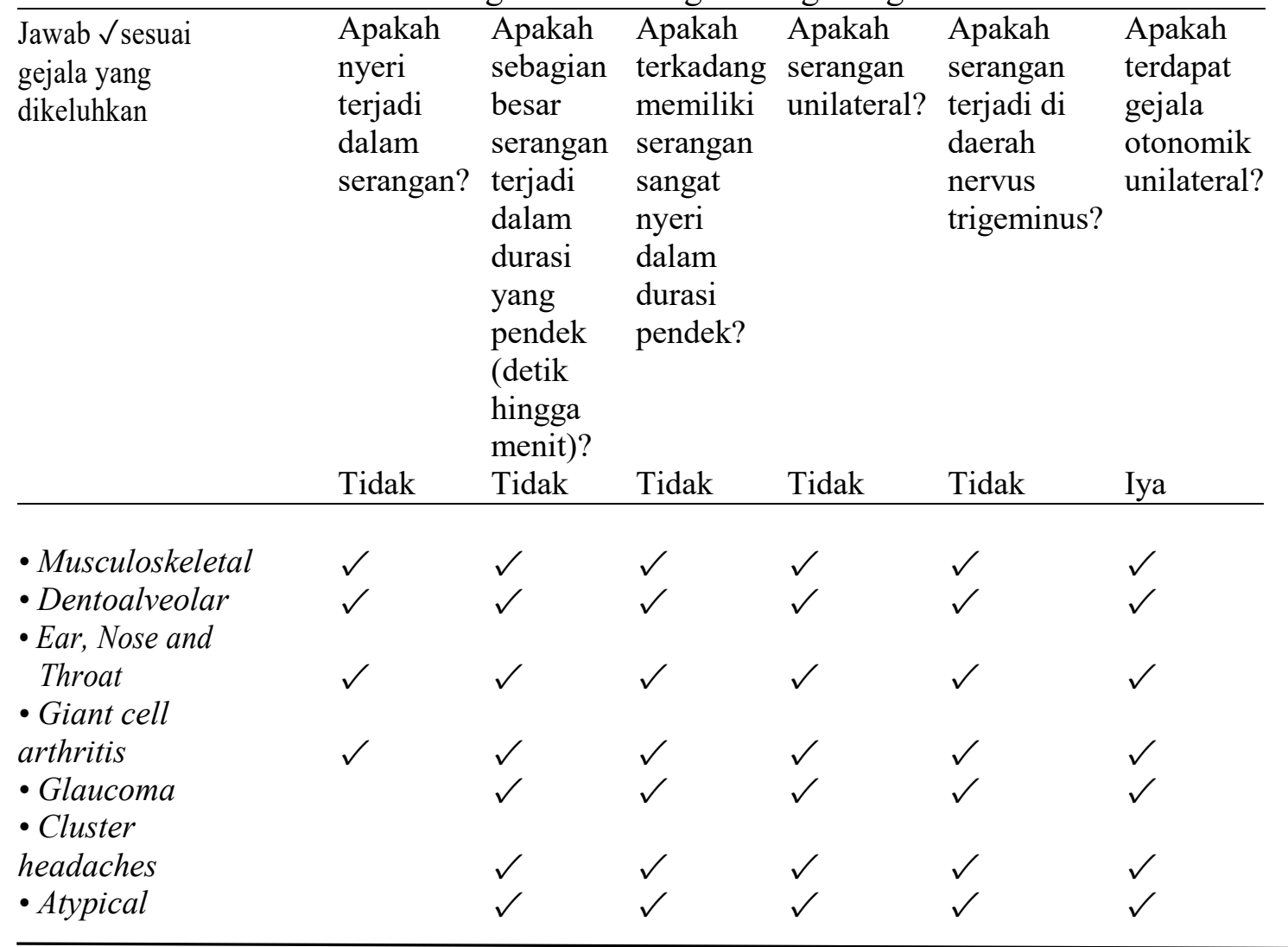

Volume 12, Nomor 1, Tahun 2020 
migraine

- Chronic paroxysmal hemicrania

- Temporomandibular joint syndrome

- Cracked tooth syndrome

- Idiopathic stabbing headache

- Glossopharyngeal neuralgia

- Nervus Intermedius neuralgia

- SUNCT

- Trigeminal neuropathy

- Atypical trigeminal neuralgia

- Typical trigeminal neuralgia

\section{DAFTAR PUSTAKA}

1. Zundert, J., et al. Evidence-Based Interventional Pain Medicine. According to Clinical Diagnosis, (John Wiley \& Son, Oxford, 2012)

2. Awad, T. \& Mohamed, K. Complementary Fluoroscopic Guided Approach to Target the Foramen Ovale in Percutaneous Trigeminal Rhizotomy. Egypt Journal of Neurosurgery 31, 105110 (2016)

3. Waldman, S. Pain Review, (Saunders elsevier, Philadelpia, 2009)

4. Akbas, M., Salem, H., Emara, T., Dinc, B. \& Karsli, B. Radiofrequency thermocoagulation in cases of atypical trigeminal neuralgia: a retrospective study. The Egyptian Journal of Neurology, Psychiatry and Neurosurgery 55, 14 (2019)

5. Emril, D. \& Ho, K.-Y. Treatment of trigeminal neuralgia: role of radiofrequency ablation. Journal of Pain Research 3, 249-254 (2010)

6. Doshi, P. \& Parikh, N. RadioFrequency Ablation of Trigeminal Ganglion for Refractory Pain of
Bilateral Trigeminal Neuralgia in a Patient with Multiple Sclerosis. Indian Journal of Pain 32, 113-115 (2018)

7. Hayek, S., Shah, B., Desai, M. \& Chelimsky, T. Pain Medicine An interdiciplinary case-based approuch, (Oxford University Press;, New York, 2015)

8. Telischak, N., et al. Fluoroscopic CArm and CT-Guided Selective Radiofrequency Ablation for Trigeminal and Glossopharyngeal Facial Pain Syndromes. Pain Medicine 19, 130-141 (2018)

9. Chen, S., et al. Percutaneous radiofrequency thermocoagulation for trigeminal neuralgia using neuronavigation-guided puncture from a mandibular angle. Medicine 95, 1-8 (2016)

10. Pauwels, L., Stewart, P., Akesson, E. \& Spacey, S. Cranial nerves. Function and Dysfunction, (People's Medical Publishing House, Connecticut, 2010)

11. Benon, H., Rathmell, J., Turk, D. \& Argoff, C. Raj's Practical Management of Pain, (Mosby Elsevier, Philadelpia, 2008) 